\section{REVISTA Mario Alario JURIDICA D'Filippo}

\title{
Efectividad de la consulta previa del proyecto Sociedad Portuaria Puerto Bahía, en el corregimiento de Pasacaballos de la Ciudad de Cartagena $^{1}$
}

\author{
Efficacy of the prior consultation of the project "Port Society Puerto \\ Bahia”, within the township Pasacaballos, city of Cartagena
}

\author{
Karen Margarita Páez Payares ${ }^{2}$ iD , Rosa Amelia Macías Seguanes $^{3}$ iD \& William Matson \\ Ospino $^{4}$ iD \\ Universidad Libre - Colombia
}

\begin{abstract}
RESUMEN
El objetivo propuesto en esta investigación consiste, en examinar la efectividad de la consulta previa realizada en el corregimiento de pasacaballos, de la ciudad de Cartagena con motivo del proyecto Sociedad Portuaria Puerto Bahía; para ello la metodología empleada fue la de la investigación socio jurídica y aplicada para el derecho y las técnicas de recolección de la información fueron las primarias ya que se aplicaron encuestas sociales a integrantes de la base social que viven en dicha localidad, para establecer su percepción sobre el grado de cumplimiento de los compromisos adquiridos por la Sociedad Portuaria Puerto Bahía en la Consulta Previa realizada por su Consejo Comunitario, y medir estadísticamente su impacto en el desarrollo socioeconómico de dicha comunidad; además se utilizaron fuentes secundarias como la ficha bibliográfica que permitió realizar un análisis de contenido a libros, capítulos de libros y artículos científicos y elaborar así el estado de la discusión sobre la consulta previa en Colombia a nivel normativo, jurisprudencial y doctrinal. Encontramos que los resultados de las encuestas sociales aquí analizadas estadísticamente denotan según el sentir de los encuestados, el poco desarrollo social del corregimiento mencionado entre los años 2014 a 2018, aun cuando el proyecto en mención, durante el desarrollo de la consulta previa realizada por el consejo comunitario pactó unas compensaciones proporcionales al daño recibido por los afrodescendientes que allí habitan, dada la imposibilidad de gozar y usar su territorio, por poner en riesgo su vida debido a la instalaciones portuarias que tiene una terminal de líquidos al granel, que además durará instalado por tiempo indeterminado.
\end{abstract}

Palabras clave: Desarrollo social; afrodescendientes; consulta previa; consejo comunitario; cultura ancestral; estado social de derecho.

\footnotetext{
${ }^{1}$ El presente articulo corresponde a un producto generado en el desarrollo de un proceso de investigación de la Maestría en Derecho Administrativo de la Universidad Libre, en cabeza del grupo de investigación Teoría del Derecho y Derechos Fundamentales PHRONESIS. Dicho proceso estuvo bajo la dirección y tutoría del Dr. Yezid Carrillo de la Rosa, en aplicación de la línea de investigación "Derechos Fundamentales y Derechos Sociales".

2 Abogada y Magister en Derecho Administrativo (C) de la Universidad Libre Sede Cartagena. karenm.paezp@unilibre.edu.co

${ }^{3}$ Abogada y Magister en Derecho Administrativo (C) de la Universidad Libre Sede Cartagena. rosy_619@hotmail.com

${ }^{4}$ Abogado y Magister en Derecho Administrativo (C) de la Universidad Libre Sede Cartagena. williamsmatson@yahoo.es
} 


\begin{abstract}
The objective proposed in this research consists in examining the effectiveness of the prior consultation carried out in the town of Pasacaballos, in the city of Cartagena on the occasion of the Puerto Bahía Port Society project; For this, the methodology used was that of socio-legal and applied research for the law and the techniques for collecting information were the primary ones since social surveys were applied to members of the social base who live in that town, to establish their perception on the degree of fulfillment of the commitments acquired by the Puerto Bahía Port Society in the Prior Consultation carried out by its Community Council, and statistically measure its impact on the socioeconomic development of said community; In addition, secondary sources were used, such as the bibliographic file, which allowed a content analysis of books, book chapters, and scientific articles to be carried out and thus elaborated the status of the discussion on prior consultation in Colombia at the normative, jurisprudential and doctrinal level. We find that the results of the social surveys analyzed here statistically denote, according to the feelings of the respondents, the little social development of the mentioned district between the years 2014 to 2018, even when the Puerto Bahía Port Society project, during the development of the prior consultation carried out The community council agreed to compensation proportional to the damage received by the Afro-descendants who live there, given the impossibility of enjoying and using their territory, for putting their lives at risk due to the port facilities that have a bulk liquids terminal, which also it will last installed indefinitely.
\end{abstract}

Keywords: Social development; afro-descendants; prior consultation; community council; ancestral culture; social state of law.

\title{
1. INTRODUCCIÓN
}

El corregimiento de Pasacaballos en la ciudad de Cartagena, es un territorio ancestral que hoy alberga a muchos afrodescendientes sumidos en la pobreza, aunque este es un espacio social (Moreno et al, 2001) que debe vivir de las regalías que producen las industrias que están ubicadas en la zona industrial de Mamonal dentro de su espacio geográfico; pero muy al contrario, su comunidad no es tenida en cuenta para el desarrollo de obras de infraestructuras, que generen empleabilidad en sus moradores y otros estados de bienestar estipulados en el estado de bienestar consagrado en el artículo $2^{\circ}$ de la Constitución de 1991, como obras para la salud o para la recreación y el deporte.

Mamonal es la zona de la industria pesada (Petroquímica) que se ha instalado en el corralito de piedra y aunque cuenta en su haber con 35 años de existencia, continua creciendo pues allí han funcionado grandes empresas como Abocol, Agafano, Biofilm, Cabot, Cartagas, Ciba Geigy, Colclinker y Conastil, entre otras y hoy en su zona se ubica la zona franca "La Candelaria", en la que operan una varias industrias que generan más de cincuenta mil empleos directos y muchos de estos, no están a disposición de los habitantes 
de Pasacaballo; Dexton por ejemplo, producirá películas de PVC; Comai, procesa compuestos de polipropileno para obtener plástico y Colissin, producirá fórmica con proyección de exportación. También está allí ubicada Petroquímica, que cuenta con una de las industrias más importantes para producir PVC de emulsión y comenzaron a operar la Promotora Eléctrica de Cartagena (Proeléctrica), primera empresa privada de generación de energía eléctrica y la refinería de Ecopetrol. Mucho de lo anteriormente dicho se contrasta en prensa como el periódico El Tiempo que tiene un articulo web titulado Mamonal a la vanguardia (Mamonal a la vanguardia, 1993)

Pasacaballos tiene en su haber, 273 años de fundado y en promedio cuenta con 4.459 viviendas correspondidas territorialmente a la Localidad No 3 y sus habitantes se encuentran ubicados en el Sisbén en el estrato 1, y además de ser vecino la zona industrial de Mamonal está rodeado de cuerpos de agua como el Canal del Dique y la bahía de Cartagena, lo que le endilga tener puertos y sociedades portuarias en su vecindario; también es colindante de la isla Barú, de la vereda Membrillal y de los barrios Policarpa y Arroz Barato, según Álvarez (2017)

Uno de estos puertos marítimos vecino de Pasacaballos es la sociedad portuaria Puerto Bahía, al que el INCO hoy ANI (Agencia Nacional de Infraestructura) otorgó un contrato de concesión portuaria, con la cual autorizó la concesión de manera temporal de una playa de uso público y otros terrenos de bajamar con sus zonas accesorias de la bahía interna de Cartagena en el sitio al que llaman "La Pulga", para que se construyera un terminal portuario multipropósito para el servicio público, entre la desembocadura del Canal del Dique y Bahía Honda corregimiento de Santa Ana en Cartagena.

Los pobladores de Pasacaballos son activistas cívicos y ya se encuentran vinculados al Consejo Comunitario que deben organizar como población afro que son. Básicamente es una comunidad de pescadores y agricultores que poco a poco se fueron viendo envueltos en la dinámica que encierra la zona industrial de Mamonal, algunos nativos se prepararon y lograron integrar a las filas de trabajadores de la zona industrial, pero lo común sigue siendo que poco participen de ese sector laboral.

Revisar la problemática que vive hoy esta comunidad afrodescendiente de la Costa Caribe colombiana, se propuso como investigación para la Maestría de Derecho Administrativo, el desarrollo de una indagación que permitiera el análisis del desarrollo social del corregimiento de Pasacaballos en Cartagena durante los años 2014 a 2018, sobre todo después que se efectuara la consulta previa, que es a través de las normas y la jurisprudencia, sobre todo la de la Corte Constitucional, llega a convertirse en un requisito de procedibilidad según Rey Quevedo (2016) por pate del Consejo Comunitario de la mencionada localidad y se acordaron unos beneficios económicos 
compensatorios por la ejecución del proyecto sociedad portuaria Puerto Bahía.

Este es un problema de investigación que es del interés de los investigadores, teniendo en cuenta que inclusive en términos medioambientales, se ha llevado a cabo un conflicto en el territorio de la comunidad de Pasacaballos, ya que por la implementación de camaroneras, tales como, Antillana, Vikingos, Atunes de Colombia en la zona industrial de Mamonal, etc., ha desaparecido mucha de la fauna marina del territorio costero como el cangrejo, además de otras especies de mamíferos y felinos, y hasta animales de monte como la hicotea, el armadillo, el ñeque, la iguana y el conejo han desaparecido de esta zona, no solo por las grandes infraestructuras construidas para las industrias, sino por la contaminación del agua que circunda a la zona industrial de Mamonal también altamente contaminada por desechos industriales, así como del aire que produce que aves como la paloma guaquera, la torcaza, el loro guacamayo entre otros se hayan extinguido y ahora se lucha por la preservación del suelo comunero de los afrodescendientes y su desarrollo social.

En la actualidad en Pasacaballos hay un conflicto por la tierra, y es por el cambio de uso del suelo y la playa de bajamar, que ya no es para la pesca artesanal que sustenta el alimento cotidiano de los afrodescendientes sino que el gobierno lo otorga en concesiones para crear puertos marítimos que enriquecen a pocos, contaminan el ambiente y poco favorece al progreso de la calidad de vida de los que habitan en este territorio ancestral aunque se lleve a cabo la consulta previa, que según (Rey Quevedo, 2016) ha sido elevada a la categoría de derecho fundamental, ese del que gozan las comunidades indígenas, afrodescendientes, raizales, ROM, etc., ya que les da protección especial al ser consultadas previamente antes de poner en marcha un proyecto, obra o actividad en sus comunidades, y es que el territorio solicitado por el Consejo Comunitario hace parte de complejos cenagosos que están siendo utilizados por agentes externos a la comunidad para la construcción de estos muelles y puertos alternos a la sociedad portuaria regional de Cartagena, y a los nativos no se les está permitiendo el acceso a ellas; es por ello que la formulación del problema se presenta de la siguiente manera: ¿Ha sido efectiva la consulta previa realizada por el consejo comunitario del corregimiento de Pasacaballos, por la construcción de la concesión de la sociedad portuaria, Puerto Bahía?

El objetivo general fue, establecer la efectividad de la consulta previa realizada por el consejo comunitario del corregimiento de Pasacaballos, por la construcción de la concesión de la sociedad portuaria puerto bahía y los objetivos específicos fueron, constituir el marco normativo sobre la consulta previa en Colombia, realizar un análisis de la doctrina jurisprudencial de la Corte Constitucional sobre las consultas previas que se han realizado en Cartagena de Indias e Indagar la percepción de los afrodescendientes que 
habitan el Pasacaballos el grado de cumplimiento de los compromisos adquiridos por la Sociedad Portuaria Puerto Bahía en la consulta previa realizada por su consejo comunitario para determinar si ha impactado el desarrollo socioeconómico de dicha comunidad. La hipótesis fue, que en Cartagena por ser una ciudad costera y muy turística, se han realizado muchas consultas previas en territorios de pueblos afrodescendientes de origen ancestral africano, temática que es de extrema importancia porque se mantiene latente pero que no ocupa un lugar en las agendas de política pública de los gobernantes de turno en el corralito de piedra, y que causa un gran malestar por estar concebida como parte esencial del procedimiento administrativo para el licenciamiento de la utilización de los recursos naturales y marinos de la ciudad amurallada, que precisamente coinciden con el lugar de asentamiento de pueblos tribales y afrodescendientes, sitios en los que constantemente se pretenden adelantar proyectos portuarios y marítimos y otras obras de infraestructuras hoteleras y de desarrollo urbanístico; actividades que impactan los territorios ancestrales de estas comunidades y como estas intervenciones responden casi siempre a temas de desarrollo económico, por ende, los gobiernos se preocupan por impulsar dicho desarrollo y no por garantizar efectivamente este derecho fundamental que es de vital importancia para defender un bien mayor, como lo es nuestra identidad multicultural y pluriétnica de quienes habitan en Pasacaballos.

\section{El Dispositivo Metodológico}

Metodológicamente esta es una investigación socio jurídica y aplicada para el Derecho. Es de corte científico cuantitativo porque se aplicaron unas encuestas sociales a una muestra significativa de integrantes de la base social que habita en el Corregimiento de Pasacaballos, en la Unidad Comunera No 1 en la Localidad Histórica y del Caribe Norte de Cartagena (Bolívar) en Colombia, que permita indagar el grado de cumplimiento de los compromisos de la Sociedad Portuaria Puerto Bahía adquiridos en la consulta previa realizada por el Consejo Comunitario de Pasacaballos.

La información primaria se recogió a través de un formulario de encuestas aplicadas manualmente por los investigadores; también se utilizó fuentes de la información secundaria como las fichas bibliográficas con las cuales se recogió la información existente en documentos jurídicos, tales como, leyes, jurisprudencias y libros sobre la consulta previa, para hacer un análisis de contenido normativo sobre la información recabada en los formularios de las fichas bibliográficas.

\section{Resultados}

En este ítem se desarrollan adecuadamente las categorías de análisis, que se establecieron como objetivos especifico y que están determinadas en el plan de trabajo de la investigación, de la siguiente manera: 


\subsection{Marco normativo sobre la Consulta Previa en Colombia}

La normatividad que regula la aplicación de la consulta previa en Colombia, parte de la regla internacional estipulada en el artículo $7^{\circ}$ del Convenio 169 de la OIT suscrito por el gobierno en Ginebra (Suiza) en 1989, y su ampliación preceptiva en la Ley 21 de 1991, que ratifica dicho acuerdo dentro del ordenamiento jurídico interno en este país latinoamericano y que forma parte del bloque de constitucionalidad que la Corte Constitucional ha desarrollado sobre los derechos fundamentales de las minorías étnicas en Colombia.

A nivel del derecho interno, encontramos que la norma de normas que aunque no tiene consagrado el derecho a la consulta previa si estableció en el artículo $2^{\circ}$ el derecho de participación como un derecho fundamental dentro de los fines del Estado colombiano y el 330 que esboza que los territorios indígenas -así como los raizales, afrodescendiente, y el pueblo gitano, etc.- serán gobernados por consejos comunitarios conformados y reglamentados según los usos y costumbres de sus comunidades. La misma norma de normas, declara que este país tiene un Estado multiétnico y pluricultural (7) y reconoce la autodeterminación de los pueblos para el goce de la soberanía (art, 9), también protege la diversidad cultural (arts. 1 7, 70) y el constituyente primario impone al Estado la obligación de proteger el patrimonio cultural y natural (art. 8,11) y se reconoce la comunidad como sujeto colectivo (art 7) titular de los derechos fundamentales.

En la Ley 70 de 1993, que se conoce como ley de negritudes, regula además el reconocimiento de la propiedad colectiva que las comunidades negras tienen por la prevalencia sobre su territorio porque es ancestral, como ocurren en el corregimiento de Pasacaballos, en Cartagena.

También el decreto 2893 de 2011 (artículo 13 núm. 7) adujo que en la Dirección de Asuntos Indígenas, Rom y Minorías en el Ministerio del Interior se coordinará la realización de los métodos de consulta previa para la promoción de decisiones legislativas y administrativas en el orden nacional; y la Ley 1437 de 2011 o Código de Procedimiento Administrativo y de lo Contencioso Administrativo consagra en varios de sus artículos el procedimiento de la consulta previa.

\subsection{Doctrina jurisprudencial de la Corte Constitucional sobre las consultas previas que se han realizado en Cartagena de Indias}

Una vez examinado el problema jurídico y la normativa que lo regula, se establece la necesidad de hacer una línea jurisprudencial sobre la consulta previa, haciendo un análisis de contenido a la doctrina jurisprudencial que el alto tribunal constitucional ha abonado sobre esta temática, puesto que, resulta conveniente elaborarla para comprender la posición jurisprudencial de los jueces constitucionales colombianos, en relación con este tema tan importante del derecho no solo colombiano sino latinoamericano, ya que 
según Calderón Guerra et al (2019) "la defensa de su contenido y los elementos de este derecho, han brotado de la doctrina jurisprudencial de la Corte Constitucional, que en múltiples sentencias ha declarado su trasgresión como derecho fundamental de los pueblos ancestrales, por su inadecuado trámite por parte de las autoridades públicas, sobre todo cuando hay obras de infraestructuras y desarrollo de gran envergadura".

El derecho a la consulta previa, libre e informada implica de acuerdo Bucetto (2018) que "cada vez que se pretenda adoptar medidas que puedan afectar directamente a los pueblos ancestrales, el Estado debe consultarlos mediante procedimientos culturalmente adecuados que respeten sus instituciones representativas", tal situación es la que se visualiza en las sentencias emanadas de la Corte Constitucional que respondieron al problema jurídico aquí esbozado y que tuvieron patrones fácticos similares, para crear una línea jurisprudencial sobre el derecho fundamental a la consulta previa.

Al revisar en la base de datos de las relatorías de esta alta corte y en los motores de búsqueda de la página web de esta alta corporación judicial, puesto que son la fuente oficial de la corporación que profirió la decisión, encontramos la Sentencia T-766 (2015), en la que la Corte mencionada indicó que la consulta previa cumple las siguientes funciones: a.- La de resguardar el derecho a la autodeterminación de los pueblos ancestrales, b.- La de asegurar que las colectividades que conforman comunidades tribales sean escuchados por las autoridades gubernamentales; c. Generar la protección de los derechos de los pueblos ancestrales sobre todo al de salvaguardar su territorio, d.- Ser un mecanismo jurídico importante para proteger la integridad de lo étnico, lo social, lo económico y lo cultural de las comunidades indígenas y afrodescendientes, y e.- Proteger la existencia como grupo social. Esta es entonces la sentencia fundadora de esta línea jurisprudencial.

Así mismo, se buscaron las demás decisiones judiciales que se han desarrollado por el alto tribunal constitucional sobre la temática abordada en este documento y aquellas que apoyaron las decisiones tomadas por los jueces constitucionales, para generar una "ingeniería reversa", que consiste en analizar las sentencias encontradas hasta conformar el "nicho citacional", tal como se recalcó en las Sentencias SU-383 (2003) en la cual este alto tribunal tuteló los derechos fundamentales a la diversidad e integridad étnica y cultural, a la participación y al libre desarrollo de la personalidad de los pueblos indígenas y tribales de la Amazonía colombiana, y en la Sentencia SU-039 de 1997 en la cual la Corte consideró que las colectividades indígenas dejaron de ser una realidad fáctica y legal para convertirse en sujetos de derechos fundamentales; es la comunidad misma que la que tiene carácter singular para hacerle el reconocimiento que la Constitución hace a la diversidad étnica y cultural de la nación colombiana, convirtiéndose esta en la sentencia consolidadora de la línea mencionada. 
A continuación, se muestran las sentencias de la Corte Constitucional de Colombia en las que este alto tribunal ha ratificado que la consulta previa es un derecho fundamental y que serán objeto de análisis e inclusión a la línea jurisprudencia, empezamos por la Sentencia C-395 (2012), en la que los jueces constitucionales señalaron que este bien ius fundamental y está "destinado a asegurar los derechos de los pueblos indígenas a su territorio y a la protección de sus valores culturales, sociales y económicos, como medio para asegurar su subsistencia como grupos humanos". Esta se convierte en la sentencia arquimédica de la línea, y la utilizaremos para identificar las demás jurisprudencias que se encuentran relacionadas con el tema objeto de investigación.

En la Sentencia T-479 (2018) se instituye por el alto tribunal constitucional de Colombia, que la consulta previa es un derecho fundamental, en el caso sub iudice del fallo en comento, en el que se pretendía la realización de un proyecto de infraestructura marítima que afectaba la movilidad y la pesca de comunidades étnicas de la zona costera de Cartagena. En esta sentencia la Corte hace la revisión constitucional de los veredictos que conforman la jurisprudencia y que fueron preceptuados por el Juzgado Segundo Administrativo de Cartagena y el Tribunal Administrativo de Bolívar, en primera y segunda instancia, proporcionalmente, durante el trámite de la acción de tutela presentada por un apoderado judicial de un grupo de actores conformados por distintas comunidades étnicas y de pescadores de Cartagena, contra la Dirección de Consulta Previa del Ministerio del Interior y otros.

Lo que se defiende jurídicamente en esta providencia es, que los accionantes aducen pertenecer a colectividades pesqueras y afrodescendientes asentados en diversas barriadas de Cartagena, que alegan además vivir de la pesca en el interior de la Bahía de esta localidad, y que según el accionante esta actividad pesquera la ejecutan en el litoral marino que bordea de manera insular y costera esas comunidades negras, y que en 1992 a la Sociedad Portuaria Terminal Marítimo Muelles el Bosque S.A., hoy Compañía de Puertos Asociados -COMPAS S.A.-, le concedieron el contrato de concesión portuaria núm. 001 de 1992, para ocupar y utilizar en forma temporal y exclusiva para la construcción de un puerto de servicio público terrestre y acuático las playas, terrenos de bajamar y demás zonas marinas accesorias, por un plazo de 20 años y que en atención a lo establecido en el Decreto Único Reglamentario del Sector Transporte 1079 de 2015, COMPAS S.A., en 2016 solicitó a la Agencia Nacional de infraestructura -ANI- la reforma del contrato para expandir las áreas del puerto, evento que hace que se prorrogue el plazo pactado y se puedan hacer nuevas inversiones.

El derecho se desarrolló cuando el alto tribunal constitucional, confirmó el veredicto declarado por el Tribunal Administrativo de Bolívar en 2018, que anuló la sentencia de primera instancia, por medio del cual el Juzgado 
Segundo Administrativo del Circuito de Cartagena negó la acción de tutela y el problema jurídico se resolvió cuando la Corte Constitucional, adjudicó el amparo de los derechos fundamentales al debido proceso administrativo y consulta previa de los Consejos Comunitarios de Tierra Bomba, Punta Arena, Bocachica y Caño del Oro. Esta sentencia ratifica a la sentencia fundadora de la línea, porque el alto tribunal confirmó en ella, que la consulta previa es un derecho fundamental de los pueblos ancestrales.

A su vez, en la Sentencia T-197 (2016) expresó la Corte, que la consulta previa tiene como mecanismo de procedencia la acción de tutela, a pesar de existir un componente jurídico contemplado en la Ley 1437de 2011 ya que en esta sentencia la Corte confirmó que la consulta previa es un derecho fundamental cuya titularidad la tienen las comunidades nativas, negras, afrocolombianas, raizales, palenqueras y gitanas y lo que se defiende jurídicamente en esta providencia es que un representante del Consejo Comunitario de Ma-Majari del Níspero - Corregimiento de María la Baja, y otro representante del Consejo Comunitario de Flamenco, así como un representante legal de la Asociación de Pescadores y Agricultores Artesanales de Pasacaballos - (AGROPEZ), que aducen que en la certificación número 618 de 2014, la Dirección de Consulta Previa del Ministerio del Interior le comunicó a la empresa Promigas S.A. E.S.P. que en el proyecto de "construcción y operación del Gasoducto Loop San Mateo - Mamonal" se reconocía exclusivamente el registro de indígenas en la parcela La Peñata, ya que en el acto administrativo mencionado se determinó que "no se registraba presencia de comunidades Negras, Afrocolombianas, Raizales y Palenqueras en el área del proyecto construcción y operación del Gasoducto Loop San Mateo - Mamonal "; así mismo dicha construcción goza de una longitud de 190 kilómetros y enlazará las zonas de producción de los pozos de Mamey y Bonga de la empresa Hocol, con los centros industriales de la región, iniciando en el municipio de Ovejas en Sucre y termina en la zona industrial de Mamonal, en Cartagena. Es por ello por lo que la Autoridad Nacional de Licencias Ambientales - ANLA libró la Resolución número 0805 de 2015, con la cual confirió Licencia Ambiental a la empresa Promigas S.A. E.S.P. para desplegar el proyecto "Construcción y operación del Gasoducto Loop San Mateo - Mamonal”.

El derecho se desarrolló cuando los jueces constitucionales hicieron el examen del fallo en revisión, dictado por el Consejo de Estado, en la Sala de lo Contencioso Administrativo, Sección Quinta, que anuló la sentencia proferida por el Tribunal Administrativo de Bolívar, la cual amparó la protección de los derechos fundamentales al debido proceso y a la consulta previa de los Consejos Comunitarios de Ma-Majari del Níspero, del Corregimiento de Flamenco de María la Baja y de la Comunidad Negra de Pasacaballos.

El problema jurídico se resolvió cuando este alto tribunal revocó el veredicto de fecha 15 de octubre de 2015, declarada por el Consejo de Estado, 
Sala de lo Contencioso Administrativo, Sección Quinta, y el fallo proferido por el Tribunal Administrativo de Bolívar de fecha 25 de agosto de 2015, y concedió el amparo del derecho a la consulta previa a los Consejos Comunitarios de Ma-Majari del Níspero, de Flamenco y de Pasacaballo.

De igual manera, en la Sentencia T-103 (2016) la Corte reconoció que la consulta previa es un derecho fundamental innominado, de carácter colectivo, y que los titulares de estos derechos son las comunidades étnicas minoritarias de nuestro país, convirtiéndose esta en la sentencia dominante. En esta sentencia la Corte en la Sala Sexta de Revisión de la Corte Constitucional, hizo la revisión de la sentencia de segunda instancia, dada por el Juzgado Primero Civil del Circuito de Cartagena, en la acción de tutela instituida por Agustina Carmona de Manrique y Henry Guyzamano Vivas, en calidad representantes legales de los Consejos Comunitarios de Tierra Baja y Puerto Rey, contra la Empresa Aguas de Cartagena S.A. E.S.P.

Lo que se defiende jurídicamente en este fallo, es que los peticionarios solicitaban de la entidad a la que demandaron que explicara los motivos por los que no se había hecho la consulta previa en relación a la obra que ellos estaban ejecutando, que ya hoy es el emisario submarino que tiene Cartagena, que realmente en su trayecto terrestre pasa por el territorio de Puerto Rey y Tierra Baja; de igual manera los afrodescendientes que habitan en las comunidades mencionadas, desconocían el plan de manejo ambiental que se le daba al Emisario, y que probablemente les causaba diversos perjuicios, como impedirles el flujo de aguas lluvias y residuales, produciendo inundaciones y estancamiento de las aguas que caían cuando llovía.

El derecho se desarrolló en esta jurisprudencia, cuando los peticionarios solicitaron el amparo de su derecho a la consulta previa, argumentando que esta no se llevó a cabo teniendo en cuanta que en su trayecto terrestre el emisario pasa por sus territorios; además en que la empresa demandada cuando solicitó al entonces INCORA y al Ministerio del Interior que certificara la presencia de comunidades negras, teniendo como coordenadas el área de influencia del diseño del Emisario, y estas entidades certificaron que Arroyo de Piedra, Punta Canoa, La Boquilla, y Manzanillo del Mar, eran comunidades de descendencia negra pero no certificaron a las comunidades demandantes de Tierra Baja y Puerto Rey.

El problema jurídico se resolvió cuando este alto tribunal, obligó a que se hiciera la consulta de las comunidades negras de Tierra Baja y Puerto Rey, y ordenó a la empresa Aguas de Cartagena S.A. E.S.P. que, solicitara a la Dirección de Consulta Previa el Ministerio del Interior para que, convocara a los consejos comunitarios de Tierra Baja y Puerto Rey para la realización de dicha consulta, y la Alcaldía de Cartagena, como responsable de la prestación de los servicios públicos en el Distrito, también se constituyó parte del 
proceso de consulta previa, y debió acudir a las reuniones y firmó la protocolización de los acuerdos.

La línea jurisprudencial que la Corte Constitucional ha venido forjando sobre la consulta previa como un derecho fundamental de las comunidades indígenas, afrodescendientes, gitanas, etc., despliega en la reiteración de las sentencias arriba enunciadas, como base del nicho y posteriormente con los fallos, como la Sentencia T-376 (2012) que asume que el marco jurídico colombiano para reconocer jurídicamente este derecho se apoya legalmente en las normativas internacionales como el Convenio 169 de la OIT, así como en la norma de normas de este país, la Ley 21 de 1991 y la Ley 70 de 1993, instrumentos normativos que reiteradamente han servido de fundamento a la jurisprudencia de la Corte Constitucional para dormir conflictos sobre la consulta previa en territorios ancestrales, es por ello que esta sentencia se convierte en la sentencia hito de este análisis jurisprudencial y su contenido es obligatorio para decisiones futuras en calidad de precedente.

Lo que se defiende jurídicamente en este fallo es que un actor instauró una acción de tutela contra la Dirección Marítima de la Capitanía de Puerto del Distrito de Cartagena, porque se le vulneró sus derechos fundamentales al mínimo vital, el trabajo y el debido proceso en relación con el principio de confianza legítima; así como el derecho fundamental de los consejos comunitarios de la comunidad negra que habita en la Unidad Comunera del Gobierno Rural de La Boquilla, Localidad de la Virgen y Turística del Distrito Turístico y Cultural de Cartagena a ser consultada previa la entrega de una concesión, sobre un área de $8.194 \mathrm{mts}^{2}$ de playa en el sector de Cielo Mar ubicada en La Boquilla, a la empresa Inversiones Talarame y Compañía S.A.

El derecho se desarrolló cuando el Tribunal Administrativo de Bolívar, aceptó la demanda y en una providencia vinculó al trámite judicial a la Capitanía de Puerto de Cartagena; al Representante Legal de la sociedad Inversiones Talamare y CIA. S.C.A.; al Gerente del Hotel Las Américas Resort; y al presidente de los consejos comunitarios de la comunidad negra de la Unidad Comunera de Gobierno Rural de La Boquilla; además ofició al Ministerio del Interior y de Justicia y a la secretaria del Interior del Distrito de Cartagena para que certificaran, sobre la existencia de comunidades indígenas o afrodescendientes en la zona donde se otorgó la concesión objeto de controversia, mediante la Resolución 0497 de 2009.

El problema jurídico se resolvió cuando este alto tribunal, concedió revocar las sentencias proferidas en primera instancia por el Tribunal Administrativo de Bolívar, y en segunda instancia, por la Sección Primera del Consejo de Estado; la primera, en tanto concedió el amparo al derecho fundamental a la Consulta Previa y declaró improcedente la acción y en su lugar, declarar la carencia de objeto en relación con los derechos 
de Jovannys Pardo Castro, y conceder el derecho a la consulta previa de la comunidad negra de la Boquilla.

Todas las sentencias mencionadas, excepto la arquimédica, que es excluida por precaves razones filosóficas, se referenciaron en este examen jurisprudencial con lo cual, se establecen los llamados "puntos nodales" (López, 2006) del nicho citacional, por lo que identificadas las sentencias y realizada una lectura analítica de éstas, teniendo en cuenta la semejanza de los hechos debatidos en estos procesos y las consideraciones que disponen la ratio decidendi, que comprueban las reglas de las decisiones de este alto tribunal, se identificaron las siguientes tendencias y patrones que componen las reglas de decisión de los jueces constitucionales con respecto a la consulta previa como un derecho fundamental de los pueblos ancestrales:

Primera Postura. - La consulta previa es derecho fundamental.

Segunda Postura. - La consulta previa tiene como mecanismo de procedencia la acción de tutela, a pesar de existir un componente jurídico contemplado en la Ley 1437de 2011.

Tercera Postura. - La consulta previa es un derecho fundamental innominado, de carácter colectivo, cuyos titulares son las comunidades indígenas, negras, raizales, palenqueras y afrocolombianas.

Cuarta Postura. - La consulta previa protege los derechos fundamentales a la diversidad étnica y cultural que determina el libre desarrollo de la personalidad de los pueblos indígenas y tribales.

Quinta Postura. - Las colectividades minoritarias son sujetos de derechos fundamentales que les son protegidos mediante la consulta previa.

Sexta Postura. - La consulta previa protege los derechos de los pueblos indígenas a poseer su territorio.

Séptima Postura. - La consulta previa regula el amparo de sus valores culturales, sociales y económicos, como medio para asegurar su subsistencia como grupos humanos.

Octava Postura. - La consulta previa se apoya en instrumentos normativos internacionales $\mathrm{u}$ del ordenamiento jurídico interno que reiteradamente han servido de fundamento a la jurisprudencia de la Corte Constitucional para dormir conflictos sobre la consulta previa.

De esta manera, en el presente trabajo científico se promueve un estudio interpretativo de la doctrina constitucional, trazando una línea jurisprudencial para identificar los argumentos jurídicos que tuvo en cuenta la Corte Constitucional para la efectividad de este derecho y así revalidar la importancia para el desarrollo de las comunidades minoritarias como las indígenas, la afrodescendiente, la raizal, el pueblo ROM, etc., como dijera Córdoba Pino (2020). 


\subsection{Percepción de los afrodescendientes que habitan el Pasacaballos sobre el grado de cumplimiento de los compromisos adquiridos por la Sociedad Portuaria Puerto Bahía en la consulta previa realizada por su consejo comunitario}

En este apartado, se muestran los resultados estadísticos obtenidos de la aplicación de las encuestas que se aplicó a una muestra representativa de la base social que integra al Corregimiento de Pasacaballos en la Unidad Comunera No 1 en la Localidad Histórica y del Caribe Norte de Cartagena de Indias (Bolívar) en Colombia. Se elaboro una encuesta social, como instrumento de recolección de información con el objetivo de recabar su percepción, sobre el grado de cumplimiento de los compromisos de la Sociedad Portuaria Puerto Bahía adquiridos en la Consulta Previa realizada por el Consejo Comunitario de Pasacaballos, para determinar cómo impactaron el desarrollo socioeconómico de dicha comunidad, por ello a continuación, se relacionan los resultados de las encuestas aplicadas a una muestra representativa del $10 \%$ de la población que habita en Pasacaballos corregimiento de Cartagena, ciudad que en el último ceso del DANE de 2018 tuvo 887.946 personas censadas, por tanto los resultados estadísticos se muestran de la siguiente manera:

Gráfica No 1.- ¿En el proyecto Sociedad Portuaria de Puerto Bahía se desarrolló la consulta previa con base al criterio de derecho fundamental, desde su proyección hasta la fase de implementación?

\begin{tabular}{ccc}
\hline OPCIÓN & FRECUENCIA & PORCENTAJE \\
\hline $\mathrm{Si}$ & 95 & $95 \%$ \\
\hline No & 5 & $5 \%$ \\
\hline TOTAL & $\mathbf{1 0 0}$ & $\mathbf{1 0 0 \%}$ \\
\hline
\end{tabular}

Fuente: Encuestas realizadas a la población investigada.

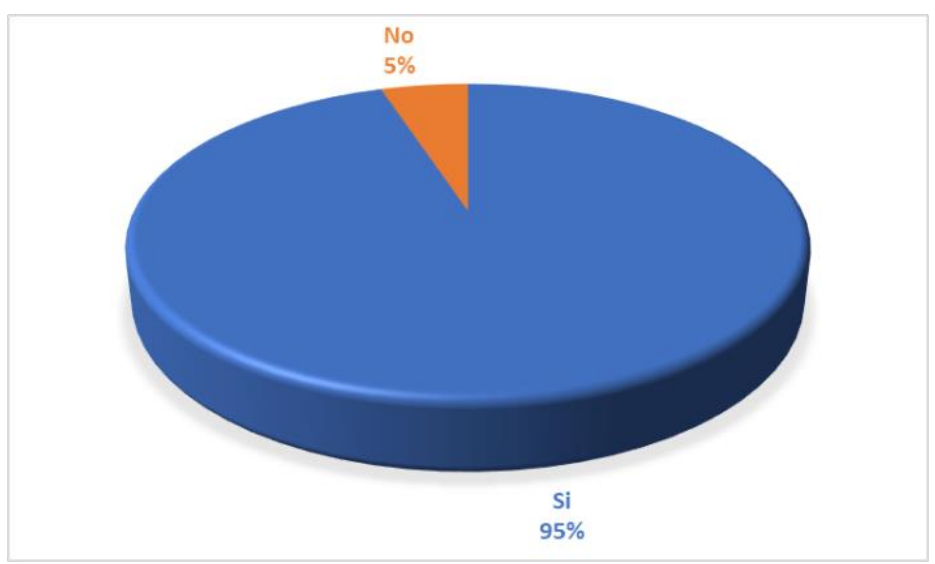

Los encuestados, integrantes de la base social que integra al Corregimiento de Pasacaballos en la Unidad Comunera No 1 en la Localidad Histórica y del Caribe Norte de Cartagena de Indias, dijeron que en el proyecto Sociedad Portuaria de Puerto Bahía se desarrolló la consulta previa con base al criterio de derecho fundamental, desde su proyección hasta la fase de implementación; Si en un $95 \%$ y que No en un $5 \%$. 
Gráfica No 2.- ¿La consulta previa se realizó entre los constructores del proyecto Sociedad Portuaria de Puerto Bahía y el consejo comunitario de Pasacaballos, bajo los criterios de diálogo entre iguales?

\begin{tabular}{ccc}
\hline OPCIÓN & FRECUENCIA & PORCENTAJE \\
\hline $\mathrm{Si}$ & 6 & $6 \%$ \\
\hline No & 94 & $94 \%$ \\
\hline TOTAL & $\mathbf{1 0 0}$ & $\mathbf{1 0 0 \%}$ \\
\hline
\end{tabular}

Fuente: Encuestas realizadas a la población investigada.

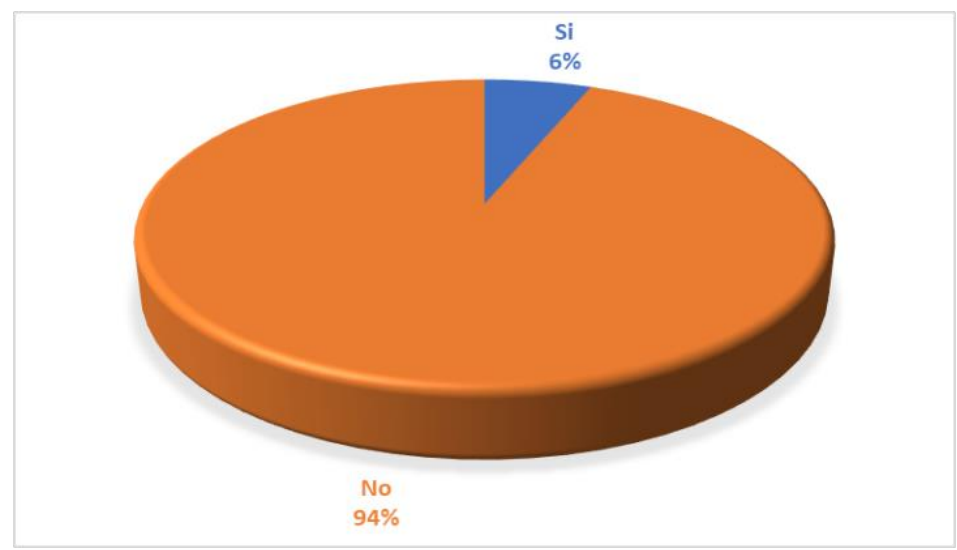

Los encuestados, integrantes de la base social que integra al Corregimiento de Pasacaballos en la Unidad Comunera No 1 en la Localidad Histórica y del Caribe Norte de Cartagena de Indias, dijeron que la consulta previa se realizó entre los constructores del proyecto Sociedad Portuaria de Puerto Bahía y el consejo comunitario de Pasacaballos, bajo los criterios de diálogo entre iguales; Si en un $6 \%$ y que No en un $94 \%$.

Gráfica No 3.- ¿La consulta previa se asimiló a meros trámites administrativos, reuniones informativas o actividades afines?

\begin{tabular}{ccc}
\hline OPCIÓN & FRECUENCIA & PORCENTAJE \\
\hline $\mathrm{Si}$ & 91 & $91 \%$ \\
\hline No & 9 & $9 \%$ \\
\hline TOTAL & $\mathbf{1 0 0}$ & $\mathbf{1 0 0 \%}$ \\
\hline
\end{tabular}

Fuente: Encuestas realizadas a la población investigada.

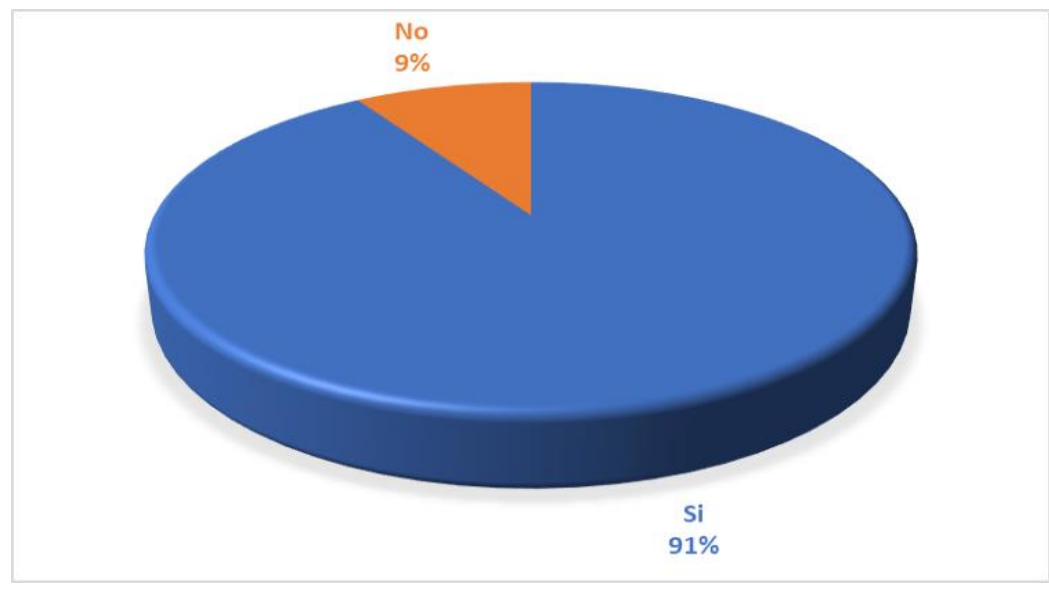


Los encuestados, integrantes de la base social que integra al Corregimiento de Pasacaballos en la Unidad Comunera No 1 en la Localidad Histórica y del Caribe Norte de Cartagena de Indias, dijeron que la consulta previa se asimiló a meros trámites administrativos, reuniones informativas o actividades afines; Si en un $91 \%$ y que No en un $9 \%$.

Gráfica No 4.- ¿Se tuvo en cuenta la importancia y el vínculo ancestral que tienen los afrodescendientes con el territorio del corregimiento de Pasacaballos y los recursos que el entorno les provee?

\begin{tabular}{ccc}
\hline OPCIÓN & FRECUENCIA & PORCENTAJE \\
\hline $\mathrm{Si}$ & 20 & $20 \%$ \\
\hline No & 80 & $80 \%$ \\
\hline TOTAL & $\mathbf{1 0 0}$ & $\mathbf{1 0 0 \%}$ \\
\hline
\end{tabular}

Fuente: Encuestas realizadas a la población investigada.

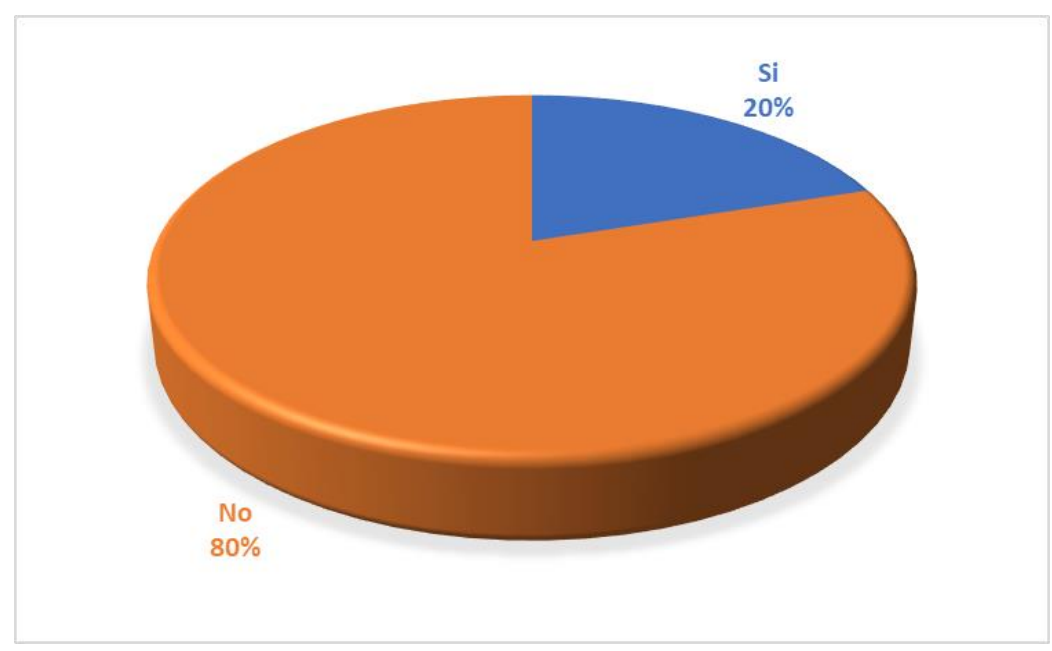

Los encuestados, integrantes de la base social que integra al Corregimiento de Pasacaballos en la Unidad Comunera No 1 en la Localidad Histórica y del Caribe Norte de Cartagena de Indias, dijeron que se tuvo en cuenta la importancia y el vínculo ancestral que tienen los afrodescendientes con el territorio del corregimiento de Pasacaballos y los recursos que el entrono les provee; Si en un $20 \%$ y que No en un $80 \%$.

Gráfica No 5.- ¿Se definió el procedimiento para la consulta previa mediante un proceso pre-consultivo y/o post-consultivo de común acuerdo con las comunidades afectadas y otros grupos?

\begin{tabular}{ccc}
\hline OPCIÓN & FRECUENCIA & PORCENTAJE \\
\hline $\mathrm{Si}$ & 65 & $65 \%$ \\
\hline No & 35 & $35 \%$ \\
\hline TOTAL & $\mathbf{1 0 0}$ & $\mathbf{1 0 0 \%}$ \\
\hline
\end{tabular}

Fuente: Encuestas realizadas a la población investigada. 


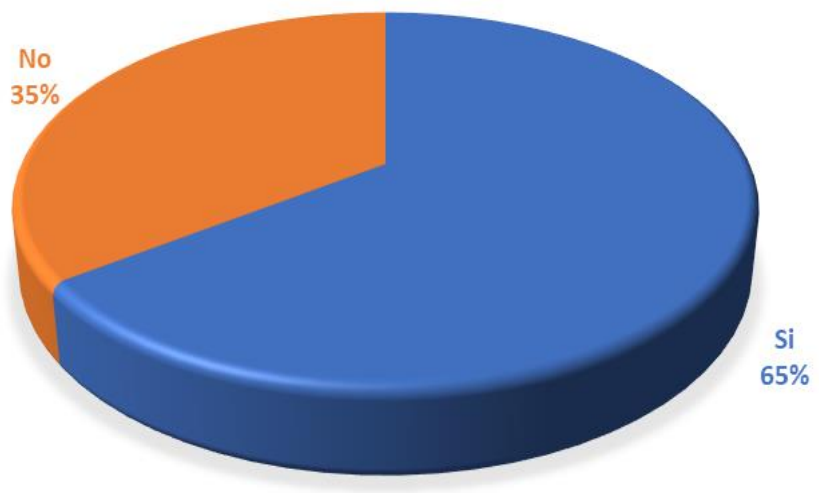

Los encuestados, integrantes de la base social que integra al Corregimiento de Pasacaballos en la Unidad Comunera No 1 en la Localidad Histórica y del Caribe Norte de Cartagena de Indias, dijeron que se definió el procedimiento para la consulta previa mediante un proceso pre-consultivo y/o postconsultivo de común acuerdo con las comunidades afectadas y otros grupos; Si en un $65 \%$ y que No en un $35 \%$.

Gráfica No 6.- ¿Participó usted en el pre-taller y taller de identificación de impactos y medidas de manejo del Proyecto de la Sociedad Portuaria de Puerto Bahía?

\begin{tabular}{ccc}
\hline OPCIÓN & FRECUENCIA & PORCENTAJE \\
\hline $\mathrm{Si}$ & 9 & $9 \%$ \\
\hline No & 91 & $91 \%$ \\
\hline TOTAL & $\mathbf{4 0}$ & $\mathbf{1 0 0 \%}$ \\
\hline
\end{tabular}

Fuente: Encuestas realizadas a la población investigada.

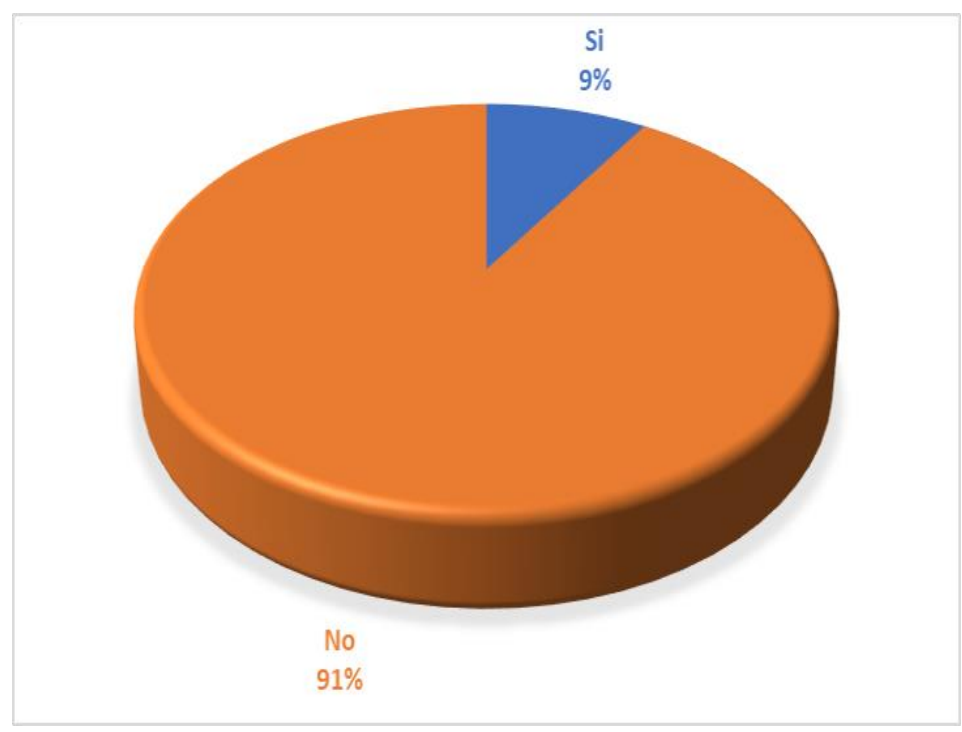

Los encuestados, integrantes de la base social que integra al Corregimiento de Pasacaballos en la Unidad Comunera No 1 en la Localidad Histórica y del 
Caribe Norte de Cartagena de Indias, dijeron participar en el pre-taller y taller de identificación de impactos y medidas de manejo del Proyecto de la Sociedad Portuaria de Puerto Bahía; Si en un $9 \%$ y que No en un $91 \%$.

Gráfica No 7.- ¿Estuvo usted presente en la evaluación con la comunidad acerca de los posibles impactos que pueden generarse con el desarrollo del proyecto de la Sociedad Portuaria de Puerto Bahía?

\begin{tabular}{ccc}
\hline OPCIÓN & FRECUENCIA & PORCENTAJE \\
\hline $\mathrm{Si}$ & 10 & $10 \%$ \\
\hline $\mathrm{No}$ & 90 & $90 \%$ \\
\hline TOTAL & $\mathbf{1 0 0}$ & $\mathbf{1 0 0 \%}$ \\
\hline
\end{tabular}

Fuente: Encuestas realizadas a la población investigada.

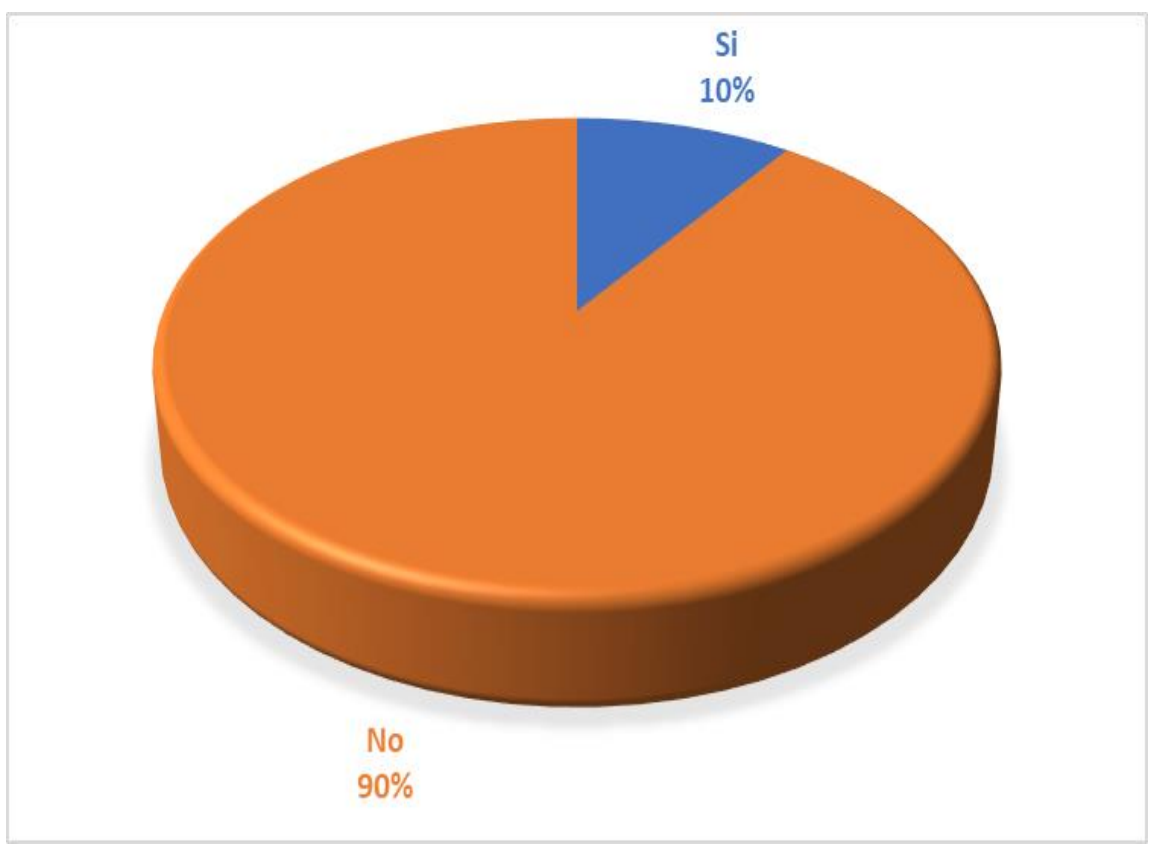

Los encuestados, integrantes de la base social que integra al Corregimiento de Pasacaballos en la Unidad Comunera No 1 en la Localidad Histórica y del Caribe Norte de Cartagena de Indias, dijeron estar presente en la evaluación con la comunidad acerca de los posibles impactos que pueden generarse con el desarrollo del proyecto de la Sociedad Portuaria de Puerto Bahía; Si en un $10 \%$ y que No en un $90 \%$.

Gráfica No 8.- ¿Cree usted que se tuvieron en cuenta los componentes abióticos, bióticos y socioeconómicos del entorno que circunda el territorio ancestral de Pasacaballo?

\begin{tabular}{ccc}
\hline OPCIÓN & FRECUENCIA & PORCENTAJE \\
\hline $\mathrm{Si}$ & 5 & $5 \%$ \\
\hline No & 95 & $95 \%$ \\
\hline TOTAL & $\mathbf{1 0 0}$ & $\mathbf{1 0 0 \%}$ \\
\hline
\end{tabular}

Fuente: Encuestas realizadas a la población investigada. 


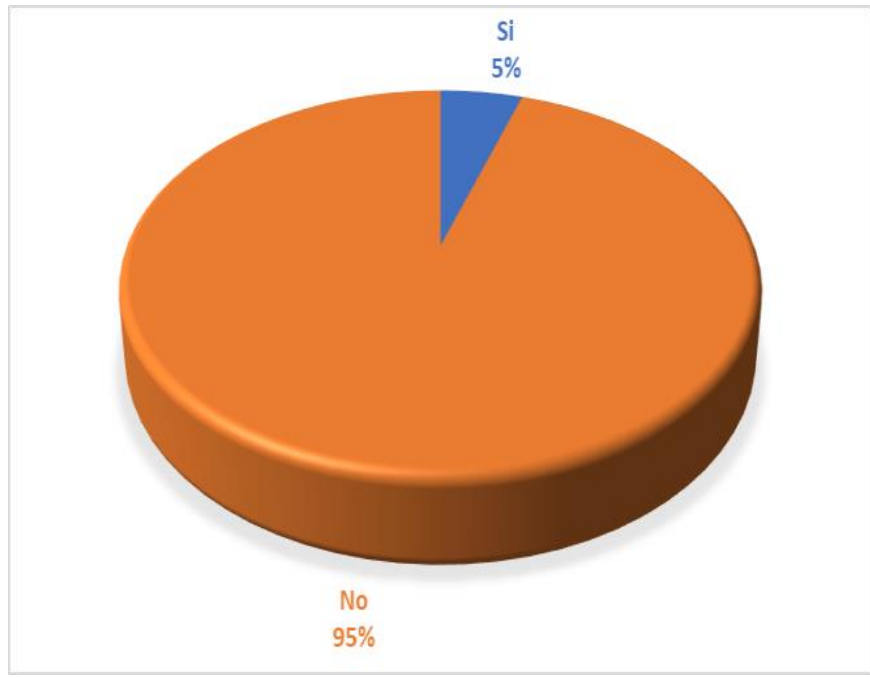

Los encuestados, integrantes de la base social que integra al Corregimiento de Pasacaballos en la Unidad Comunera No 1 en la Localidad Histórica y del Caribe Norte de Cartagena de Indias, dijeron que se tuvieron en cuenta los componentes abióticos, bióticos y socioeconómicos del entorno que circunda el territorio ancestral de Pasacaballo; Si en un 5\% y que No en un 95\%.

Gráfica No 9.- ¿Cree usted que actualmente Pasacaballo tiene obras de infraestructura en salud, recreación, deportes que denoten el desarrollo social del corregimiento?

\begin{tabular}{ccc}
\hline OPCIÓN & FRECUENCIA & PORCENTAJE \\
\hline $\mathrm{Si}$ & 3 & $3 \%$ \\
\hline No & 97 & $97 \%$ \\
\hline TOTAL & $\mathbf{1 0 0}$ & $\mathbf{1 0 0 \%}$ \\
\hline
\end{tabular}

Fuente: Encuestas realizadas a la población investigada.

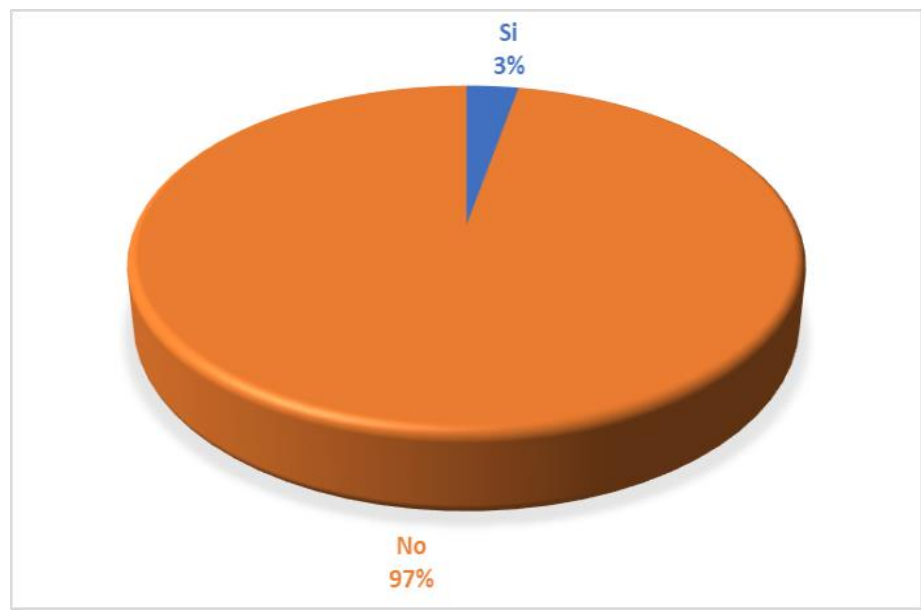

Los encuestados, integrantes de la base social que integra al Corregimiento de Pasacaballos en la Unidad Comunera No 1 en la Localidad Histórica y del Caribe Norte de Cartagena de Indias, dijeron que actualmente Pasacaballo tiene obras de infraestructura en salud, recreación, deportes que denoten el desarrollo social del corregimiento; Si en un 3\% y que No en un $97 \%$. 
Gráfica No 10.- ¿Cree usted que los procesos de desarrollo que se acordaron con el gerente de la Sociedad Portuaria Puerto Bahía como resultado de la Consulta Previa que se realzado para evaluar la factibilidad de ejecución del proyecto en el territorio ancestral de Pasacaballo se han cumplido?

\begin{tabular}{ccc}
\hline OPCIÓN & FRECUENCIA & PORCENTAJE \\
\hline $\mathrm{Si}$ & 10 & $10 \%$ \\
\hline No & 90 & $90 \%$ \\
\hline TOTAL & $\mathbf{1 0 0}$ & $\mathbf{1 0 0 \%}$ \\
\hline
\end{tabular}

Fuente: Encuestas realizadas a la población investigada.

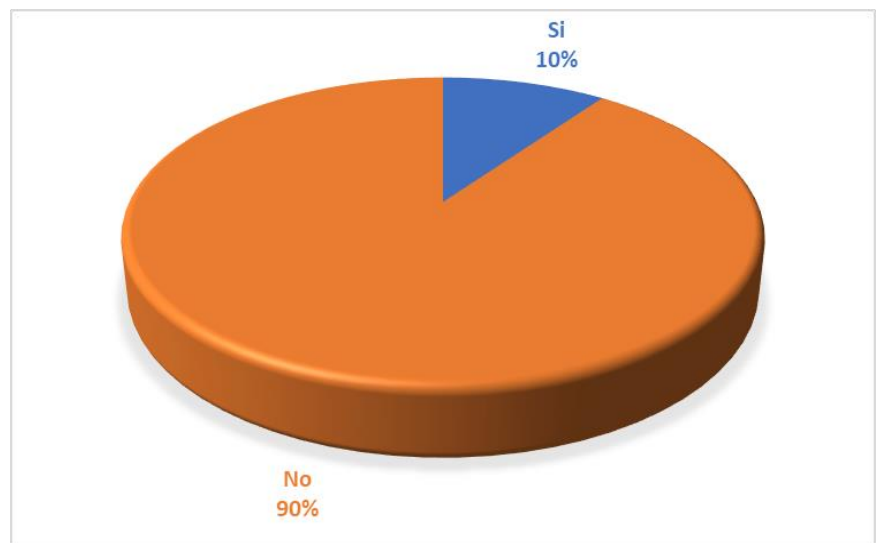

Los encuestados, integrantes de la base social que integra al Corregimiento de Pasacaballos en la Unidad Comunera No 1 en la Localidad Histórica y del Caribe Norte de Cartagena de Indias, dijeron que los procesos de desarrollo que se acordaron con el gerente de la Sociedad Portuaria Puerto Bahía como resultado de la Consulta Previa que se realzado para evaluar la factibilidad de ejecución del proyecto en el territorio ancestral de Pasacaballo se han cumplido; Si en un $10 \%$ y que No en un $90 \%$.

\section{Discusión}

En la actualidad en el corralito de piedra hay un conflicto por la tierra que está ubicada en la zona costera sobre todo la insultar, que está ubicada en la bahía interna de Cartagena y que está produciendo un cambio de uso del suelo y la playa de bajamar, que ya no es para la pesca artesanal que sustenta el alimento cotidiano de los afrodescendientes sino que el gobierno está otorgando concesiones para crear muelles y puertos marítimos que enriquecen a pocos, pero contaminan el ambiente y poco contribuye al mejoramiento de la calidad de vida de los que habitan en estas localidades aledañas a los cuerpos de agua internos de la bahía inclusive, como los que viven en Pasacaballos.

Es por ello que en esta investigación se hizo a su vez, un estudio de caso que permitió indagar sobre la efectividad de la consulta previa del proyecto sociedad portuaria Puerto Bahía, en el corregimiento de Pasacaballos de la ciudad de Cartagena, lugar en que se aplicaron por los investigadores unas 
encuestas sociales, y sobre las cuales los integrantes de la base social que integra al Corregimiento de Pasacaballos en la Unidad Comunera No 1 en la Localidad Histórica y del Caribe Norte de Cartagena de Indias, dijeron que en el proyecto Sociedad Portuaria de Puerto Bahía se desarrolló la consulta previa con base al criterio de derecho fundamental, desde su proyección hasta la fase de implementación; Si en un $95 \%$ y que No en un $5 \%$ lo que hace inferir que en la consulta previa solo participaron los integrantes de la junta directiva del consejo comunitario y su representante legal (Manuel Ahumedo Sosa) pero que no a toda la comunidad que habita en la localidad se le socializó dicho proyecto y también dijeron que la consulta previa se realizó entre los constructores del proyecto Sociedad Portuaria de Puerto Bahía y el consejo comunitario de Pasacaballos, bajo los criterios de diálogo entre iguales; Si en un $6 \%$ y que No en un $94 \%$, ya que tal como se dijo en el ítem antes mencionado, el dialogo solo fue entre los directivos del proyecto portuario y la junta directiva, lo que hace que dicho dialogo haya sido realizado en medio de las diferencias sociales.

Los encuestados, dijeron además que la consulta previa se asimiló a meros trámites administrativos, reuniones informativas o actividades afines; $\mathrm{Si}$ en un $91 \%$ y que No en un $9 \%$ y es lo que los investigadores lograron observar en las actas de la consulta previa, ya que tuvieron acceso a ellas y los encuestados dijeron también que se tuvo en cuenta la importancia y el vínculo ancestral que tienen los afrodescendientes con el territorio del corregimiento de Pasacaballos y los recursos que el entorno les provee; Si en un $20 \%$ y que No en un $80 \%$, porque el gobierno a través de la ANI dio paso a la concesión portuaria en donde se construyó un nuevo puerto para la ciudad de Cartagena, evento que hizo que se aminoraran las posibilidades de pesca artesanal en la zona de bajamar de Pasacaballo.

Así mismo dijeron los encuestados, que se definió el procedimiento para la consulta previa mediante un proceso pre-consultivo y/o post-consultivo de común acuerdo con las comunidades afectadas y otros grupos; $\mathrm{Si}$ en un $65 \%$ y que No en un $35 \%$, ya que en las actas observadas por los investigadores también se visualiza que además del consejo comunitario de Pasacaballo se citaron a la consulta previa a los consejos comunitarios de otros grupos afrodescendientes ubicados en la zona insular como Araca, Santa Ana, Barú y Bocachica; también dijeron participar en el pre-taller y taller de identificación de impactos y medidas de manejo del Proyecto de la Sociedad Portuaria de Puerto Bahía; Si en un $9 \%$ y que No en un $91 \%$, porque solo participaron los integrantes de las juntas directivas de los consejo comunitarios convocados y no todas las personas que conforman la base social de las comunidades afectadas como Pasacaballos.

Los encuestados, dijeron estar presente en la evaluación con la comunidad acerca de los posibles impactos que pueden generarse con el desarrollo del proyecto de la Sociedad Portuaria de Puerto Bahía; Si en un $10 \%$ y que No 
en un $90 \%$, y que se tuvieron en cuenta los componentes abióticos, bióticos y socioeconómicos del entorno que circunda el territorio ancestral de Pasacaballo; Si en un 5\% y que No en un $95 \%$, y es solo observar el paisaje que cubre el entorno costero de Cartagena, para entender el daño que se le hace a las comunidades afrodescendientes cuando se autorizan concesiones y licencias ambientales tanto para sociedades portuarias como para construcción de obras de infraestructura, porque las ya autorizadas han dejado graves impactos en los ecosistemas marinos y todo el ambiente marino costero en general, ya que la flora y fauna fue desmantelada y por este motivo ya no hay árboles ni vegetación nativa que forman parte del territorio y es de la esencia de la comunidad por los proyectos autorizados por el gobierno nacional, regional o local.

Los encuestados, dijeron que actualmente Pasacaballo tiene obras de infraestructura en salud, recreación, deportes que denoten el desarrollo social del corregimiento; Si en un $3 \%$ y que No en un $97 \%$, por lo que se infiere siguiendo a Robayo Contreras (2015) que la consulta previa es garantía de los derechos fundamentales de las minorías étnicas del país, por eso no es del interés ni del Estado ni de quienes lo administran revisar que estas se lleven a cabo, y cuando se ordena su puesta en marcha ya se ha causado un daño ambiental, social, cultural a estos grupos étnicos, es por ello que este derecho no es eficaz porque no se cumple lo normado en la ley de hacerse previo a que se adopte cualquier medida administrativa o legislativa, inclusive se decidan implementar proyectos que puedan afectarles.

Los encuestados, dijeron que los procesos de desarrollo que se acordaron con el gerente de la Sociedad Portuaria Puerto Bahía como resultado de la Consulta Previa que se realzado para evaluar la factibilidad de ejecución del proyecto en el territorio ancestral de Pasacaballo se han cumplido; Si en un $10 \%$ y que No en un $90 \%$, lo que hace intuir que en el proceso consultivo participan los sujetos colectivos, es decir, aquellos que tienen la titularidad y la capacidad para actuar respecto del derecho de consulta previa (Morales, 2013) dicho en otras palabras los grupos étnicos que dentro del entorno colombiano se reconocen como tal, no solo el representante legal o la junta directiva del consejo comunitario.

Este documento científico examina la correlación entre los proyectos de desarrollo en la ciudad de Cartagena y la vulneración de los derechos de las comunidades afrodescendientes, como a la consulta previa, ya que o no se les ha tenido en cuenta al no llevarse a cabo esta o esta se ha hecho al acomodo de los dueños del proyecto que se va a implementar, ya que los mismo son autorizados por el gobierno a través de las licencias ambientales y concesiones, generando problemas en analogía con el derecho fundamental a la consulta previa que tienen los afro descendiente de los pueblos ancestrales y otros minoritarios étnicos que han resuelto esta controversia en los estados judiciales, tal como lo aduce Rodríguez (2011) 
Este análisis se orienta a fundar los exigencias mínimas que tiene la consulta previa para su ejecución y garantía de los derechos de los pueblos afrodescendientes del corregimiento de Pasacaballos en Cartagena, sobre todo en relación al territorio que es muy valioso no solo por lo que la naturaleza les brinda a través del ecosistema marino, sino porque están ubicados en la zona costera o insular de la ciudad marítima y portuaria, lo que hace que también se les vulnere la independencia, la contribución y el desarrollo local propio.

También este estudio denota la importancia de la aplicabilidad de la consulta previa en la ciudad amurallada, porque tiene un análisis de los pronunciamientos de la Corte Constitucional, que evidencia la doctrina jurisprudencial y el desarrollo que ha tenido la consulta previa en los afrodescendientes que habitan en el corralito de piedra, evidenciando cómo en la actualidad, esta figura comprende casi todas las posturas que este alto tribunal constitucional ha asumido frente a los problemas generados por la falta de coordinación y precisión de los procesos de autorización de licencias ambientales y concesiones para el desarrollo de obras de infraestructuras portuarias o industriales, inclusive hoteleras y de turismo, que afectan la identidad etnográfica de las comunidades herederas de los ancestros africanos, para afirmar su subsistencia como grupos humanos.

\section{Conclusión}

Al examinar el proceso de la consulta previa del proyecto sociedad portuaria Puerto Bahía, en el corregimiento de Pasacaballos de la ciudad de Cartagena, para determinar su efectividad, nos hace remontar a los orígenes de las comunidades afrodescendientes en Colombia, ya que es con la conquista de las Américas por parte de los españoles quienes llegaron al territorio de la Nueva Granada acompañados de los negros africanos esclavizados para que ayudaran a la colonización de este nuevo mundo que se presentaba ante la modernidad.

Los negros africanos suplieron la mano de obra indígena, que fue protegida por las Leyes de Indias que Alfonso X el sabio elaboró para que los nativos de las Américas fuesen protegidos en resguardos a través de la mita y la encomienda, luego de ser diezmada ya que el indio prefirió matarse con el invasor, dejando a los negros de nueva guinea y otros territorios tribales africanos, el espacio para su desarrollo, que era poco, ya que no tenían derechos porque eran considerados una cosa. Esta situación de esclavitud se acabó con la constitución política de 1886 que abolió en el territorio de la Nueva Granada la esclavitud y parecería que la situación de los hijos de los negros esclavos hubiese cambiado con tal acontecimiento jurídico político y no fue así, ya que fue la Constitución de 1991 la que con fundamentos en el estado social de derecho consagró derechos para las minorías étnicas, los indígenas y los afrodescendientes, y ha sido la Corte Constitucional la que a 
través de los fallos en las sentencias de revisión de acciones de tutela ha garantizado los derechos a la igualdad y contra la discriminación racial que también han ingresado al bloque de constitucionalidad.

En el caso bajo estudio, se puede concluir que la consulta previa del proyecto sociedad portuaria Puerto Bahía, en el corregimiento de Pasacaballos de la ciudad de Cartagena es parcialmente efectiva ya que se ha cumplido a medias el trámite de la consulta, vemos que se desarrolló la consulta previa con base al criterio de derecho fundamental, pero se realizó solo entre los constructores del proyecto Sociedad Portuaria de Puerto Bahía y el consejo comunitario de Pasacaballos en cabeza de su representante legal, no convocaron a toda la comunidad que vive en dicha localidad, lo que hace asumir que la consulta previa se asimiló a meros trámites administrativos, reuniones informativas o actividades afines, lo que visualiza investigativamente que se llevó a cabo el procedimiento para la consulta previa mediante un proceso pre-consultivo y/o post-consultivo de común acuerdo con los consejos comunitarios de las comunidades afectadas solamente.

Solamente los representantes legales y la junta directiva de los consejos comunitarios de grupos afrodescendientes ubicados en la zona insular como Pasacaballos, Ararca, Santa Ana, Barú y Bocachica participaron en el pretaller y taller de identificación de impactos y medidas de manejo del Proyecto de la Sociedad Portuaria de Puerto Bahía, lo anterior permite inferir que toda la comunidad no estuvo presente en la evaluación de los posibles impactos que pueden generarse con el desarrollo del proyecto portuario mencionado y tal situación se menciona en este documento porque es el territorio ancestral en su conjunto el que cuenta los componentes abióticos, bióticos y socioeconómicos que como entorno brinda a los afrodescendientes de Pasacaballo.

Se concluye entonces que la percepción que tienen las personas encuestadas es que actualmente Pasacaballo no tiene obras de infraestructura en salud, recreación, deportes que denoten el desarrollo social del corregimiento por lo que la consulta previa no es eficaz ya que los procesos de desarrollo que se acordaron con el gerente de la Sociedad Portuaria Puerto Bahía como resultado de la consulta previa que se realzado para evaluar la factibilidad de ejecución del proyecto en el territorio ancestral de Pasacaballo no se han cumplido porque nunca se pactaron el desarrollo de obras de infraestructura que permita la calidad de vida de quienes habitan esta comunidad y que descienden de los negros esclavos traídos al puerto de Cartagena por los buques y naos españolas, para que luego San Pedro Claver les curase sus heridas para ser vendidos a terratenientes españoles para el trabajo en sus haciendas.

Lo que se visualiza por los investigadores que se pactó en esta consulta previa entre el consejo comunitario y la sociedad portuaria Puerto Bahía, y que se 
observa en el Acta de entrega y/o de finalización de esta, fue la entrega una dotación de aparejos de pesca artesanal para la Asociación de pescadores de Pasacaballos y las otras comunidades insulares que también fueron convocadas en el marco de un proyecto denominado Proyecto Atarraya, y se les entregó:

- Embarcaciones de fibra de vidrio.

- Motores fuera de borda.

- Implementos de pesca.

- Compra de un lote para la Asociación.

- Apoyo para la legalización de la Asociación.

El análisis en profundidad del caso en comento, buscaba indagar a través de un estudio de percepción que fue analizado estadísticamente, si hubo participación de las comunidades afrodescendientes, es decir, si todas y todos los habitantes de Pasacaballos sabían de la consulta previa y de la envergadura de esta concesión, que se regula jurídicamente en los términos y condiciones establecidas en la Resolución 473 de 2010 según en el contrato de concesión que se menciona en este documento científico. La empresa, al no hacer consulta previa, no pagó a las comunidades lo correspondiente de las medidas de compensación, prevención o mitigación de estos impactos ya que son previsibles y que debieron ser identificados en los estudios previos a la obtención de la licencia, lo que envuelve la responsabilidad del Estado, conforme a la normativa interna e internacional.

El examen constitucional de las sentencias de revisión de acciones de tutelas ha determinado las reglas establecidas por la Corte Constitucional para efecto de respetar de manera integral y de llevar a cabo el proceso de consulta previa, desde la etapa del preacuerdo hasta la del post acuerdo, es por ello, que para el derecho colombiano esta consulta previa no es efectiva para salvaguardar los derechos de los afrodescendientes de habitan en Pasacaballo. El Estado como responsable de la garantía de derechos de los pueblos étnicos, también lo es frente al deber de vigilar que las empresas privadas respetan los derechos de los pueblos ancestrales. Para ello debe disponer de los medios que puedan ejercer un control necesario antes, durante y después de los procesos de consulta. Y que aunque en esta consulta previa hubo acompañamiento de la Defensoría del Pueblo y de otros organismos nacionales en los acuerdos y procedimientos de esta, el gobierno colombiano, está en el deber de efectuar un plan de individualización de los territorios colectivos y ancestrales ocupados por población afrocolombiana como la que habita en Pasacaballo para que todos estén enterados de lo que ocurre en su territorio.

El gobierno debe además garantizar la participación y ejecución de la consulta en las comunidades Afro como un derecho fundamental y adoptar medidas urgentes de protección a favor de sus derechos colectivos e individuales (Corte Constitucional. Auto 073 de 2014) de allí que se concluye que la 
consulta previa del proyecto sociedad Portuaria Puerto Bahía, en el corregimiento de Pasacaballos de la ciudad de Cartagena, no es efectiva jurídicamente.

\section{Bibliografía}

Álvarez, R. D. (2017, 13 diciembre). Pasacaballos, un rico pobre. https://www.eluniversal.com.co/cartagena/pasacaballos-un-rico-pobre-267946dceu381604

Calderón Guerra, M.; Jaimes Contreras, M. (2019) La consulta previa y su reglamentación como garantía de derecho fundamental de los pueblos indígenas. Universidad Cooperativa de Colombia. Seccional Santa Marta. Facultad de Derecho.

Bucetto, M. (2018) El derecho de los pueblos indígenas a la consulta previa, libre e informada, y los principios de progresividad y no regresividad. Estudio de la aplicación práctica de los estándares fijados por el Sistema Interamericano de Derechos Humanos en Colombia. Lex N 21 - Año XVI - 2018 - I / ISSN 2313 1861.

Córdoba Pino, E. (2020). Estudio jurisprudencial sobre la consulta previa: concepto de territorio para las comunidades minoritarias de Colombia trabajo de grado para optar al título de abogado. Universidad Cooperativa de Colombia. Programa de Derecho. Quibdó.

Fajardo Rojas, L. (2017) La errónea interpretación de la jurisprudencia en relación con la consulta previa y su aplicación en el ordenamiento jurídico colombiano. Trabajo de Grado para optar al Título de Abogado. Universidad Católica de Colombia. Facultad de Derecho. Universidad Católica de Colombia. Sede Bogotá D.C.

Robayo Contreras X. (2015) Procedimiento de consulta previa dentro del estado colombiano. Universidad Militar Nueva Granada. Dirección de Posgrado. Especialización en Derecho Administrativo. Metodología de la Investigación II Bogotá D. C, octubre.

Rodríguez, G. (2011) Proyectos y conflictos en relación con la consulta previa. Jurídica, edición especial, pp. 57-72 - ISSN 1692-2530. 57 Julio-diciembre de 2011/166 p. Medellín, Colombia.

\section{Leyes:}

Organización Internacional del Trabajo. (1989). Convenio 169 suscrito en Ginebra.

Constitución Política Colombia (1991) Editorial Leyer. Bogotá. 2020

Congreso de la República de Colombia. (1991, 6 de marzo). Ley 21 de 1991. Diario Oficial. N. ${ }^{\circ} 39720$. 
Congreso de la República de Colombia. (1993, 31 de agosto). Ley 70 de 1993. Diario Oficial No. 41.013.

Presidencia de la República de Colombia. (2011, 11 de agosto). Decreto 2893 de 2011. Diario Oficial No. 48.158.

Congreso de la República de Colombia. (2011, 18 de enero). Ley 1437 de 2011 o CPACA. Diario Oficial No. 47.956.

\section{Jurisprudencia}

Corte Constitucional. Sentencia T-479 de 2018. [M.P. José Fernando Reyes Cuartas del 11 de septiembre de 2018]. Consultada el día 5 de junio de 2021, recuperado de: https://www.corteconstitucional.gov.co/relatoria/2018/T-479-18.htm

Corte Constitucional. Sentencia SU-383 de 2003. [M.P. Álvaro Tafur Galvis del 13 de mayo de 2003]. Consultada el día 5 de junio de 2021, recuperado de: https://www.corteconstitucional.gov.co/relatoria/2003/su383-03.htm

Corte Constitucional. Sentencia SU-039 de 1997. [M.P. Antonio Barrera Carbonell del 3 de febrero de 1997]. Consultada el día 5 de junio de 2021, recuperado de: https://www.corteconstitucional.gov.co/relatoria/1997/su039-97.htm

Corte Constitucional. Sentencia T-197 de 2016. [M.P. Jorge Iván Palacio Palacio del 2 de abril de 2016]. Consultada el día 5 de junio de 2021, recuperado de: https://www.corteconstitucional.gov.co/relatoria/2016/t-197-16.htm

Corte Constitucional. Sentencia T-969 de 2014. [M.P. Gloria Stella Ortiz Delgado del 15 de diciembre de 2014]. Consultada el día 5 de junio de 2021, recuperado de: https://www.corteconstitucional.gov.co/relatoria/2014/t-969-14.htm

Corte Constitucional. Sentencia T-376 de 2012. [M.P. María Victoria Calle Correa del 18 de mayo de 2012]. Consultada el día 5 de junio de 2021, recuperado de: https://www.corteconstitucional.gov.co/relatoria/2012/T-376-12.htm

\section{Cibergrafía}

Resultados Censo Nacional de Población y Vivienda 2018 Cartagena de Indias, Bolívar Julio 12 de 2019. Consultada el día 5 de junio de 2021, de: https://www.dane.gov.co/files/censo2018/informacion-tecnica/presentacionesterritorio/190712-CNPV-presentacion-bolivar.pdf
Mamonal
a $\quad$ la
vanguardia.
(1993, 30
octubre). https://www.eltiempo.com/archivo/documento/MAM-251362 